\title{
Correction to: Assessment and Obligatory Treatment of Violent and Sexually Violent Offenders
}

\author{
Ruud H. J. Hornsveld, Floris W. Kraaimaat, Luk A. C. L. Gijs, \\ and Emma J. Palmer
}

Correction to: R. H. J. Hornsveld et al. (eds.), Assessment and Obligatory Treatment of Violent and Sexually Violent Offenders, Advances in Preventing and Treating Violence and Aggression, https://doi.org/10.1007/978-3-030-27840-3

The book was inadvertently published with an incorrect affiliation for one of the volume editors, Luk A. C. L. Gijs, as "Moet zijn KU Leuven, Leuven, Belgium”. It has been updated as "KU Leuven, Leuven, Belgium" in the front matter and in Chapters 1 and 5.

The updated online version of these chapters can be found at https://doi.org/10.1007/978-3-030-27840-3_1

https://doi.org/10.1007/978-3-030-27840-3_5

https://doi.org/10.1007/978-3-030-27840-3 